\title{
Dynamic arterial elastance as a predictor of arterial pressure response to fluid administration: a validation study
}

Manuel Ignacio Monge García ${ }^{1,2 *}$, Manuel Gracia Romero ${ }^{1}$, Anselmo Gil Cano ${ }^{1}$, Hollmann D Aya², Andrew Rhodes², Robert Michael Grounds ${ }^{2}$ and Maurizio Cecconi ${ }^{2}$

\begin{abstract}
Introduction: Functional assessment of arterial load by dynamic arterial elastance $\left(E a_{d y n}\right)$, defined as the ratio between pulse pressure variation (PPV) and stroke volume variation (SW), has recently been shown to predict the arterial pressure response to volume expansion (VE) in hypotensive, preload-dependent patients. However, because both SW and PPV were obtained from pulse pressure analysis, a mathematical coupling factor could not be excluded. We therefore designed this study to confirm whether $\mathrm{Ea}_{\mathrm{dyn}}$, obtained from two independent signals, allows the prediction of arterial pressure response to VE in fluid-responsive patients.
\end{abstract}

Methods: We analyzed the response of arterial pressure to an intravenous infusion of $500 \mathrm{ml}$ of normal saline in 53 mechanically ventilated patients with acute circulatory failure and preserved preload dependence. Ea dyn was calculated as the simultaneous ratio between PPV (obtained from an arterial line) and SW (obtained by esophageal Doppler imaging). A total of 80 fluid challenges were performed (median, 1.5 per patient; interquartile range, 1 to 2). Patients were classified according to the increase in mean arterial pressure (MAP) after fluid administration in pressure responders $(\geq 10 \%)$ and non-responders.

Results: Thirty-three fluid challenges (41.2\%) significantly increased MAP. At baseline, Ea dyn was higher in pressure responders $(1.04 \pm 0.28$ versus $0.60 \pm 0.14 ; P<0.0001)$. Preinfusion $E_{a d y n}$ was related to changes in MAP after fluid administration $\left(R^{2}=0.60 ; P<0.0001\right)$. At baseline, Ea dyn predicted the arterial pressure increase to volume expansion (area under the receiver operating characteristic curve, $0.94 ; 95 \%$ confidence interval (Cl): 0.86 to $0.98 ; P<0.0001$ ). A preinfusion $\mathrm{Ea}_{\mathrm{dyn}}$ value $\geq 0.73$ (gray zone: 0.72 to 0.88 ) discriminated pressure responder patients with a sensitivity of 90.9\% (95\% Cl: 75.6 to $98.1 \%$ ) and a specificity of $91.5 \%$ (95\% Cl: 79.6 to $97.6 \%)$.

Conclusions: Functional assessment of arterial load by $\mathrm{Ea}_{\mathrm{dyn}}$, obtained from two independent signals, enabled the prediction of arterial pressure response to fluid administration in mechanically ventilated, preload-dependent patients with acute circulatory failure.

\section{Introduction}

Correction of arterial hypotension is essential for adequate cellular metabolism [1,2]. Although there is no single mean arterial pressure (MAP) value that guarantees a global perfusion pressure [3], maintaining MAP above a minimum level has been recommended in order to

\footnotetext{
* Correspondence: ignaciomonge@gmail.com
${ }^{1}$ Servicio de Cuidados Intensivos y Urgencias, Hospital SAS de Jerez, C/

* Correspondence: ignaciomonge@gmail.com
'Servicio de Cuidados Intensivos y Urgencias, Hospital SAS de Jerez, C/ Circunvalación s/n, 11407 Jerez de la Frontera, Spain ${ }^{2}$ Department of Intensive Care Medicine, St George's Healthcare NHS Trust
and St George's University of London, Blackshaw Road, Tooting, London 'Department of Intensive Care Medicine, St George's Healthcare NHS Trust
and St George's University of London, Blackshaw Road, Tooting, London SW17 OQT, UK
}

(c) 2014 García et al.; licensee BioMed Central Ltd. This is an Open Access article distributed under the terms of the Creative Commons Attribution License (http://creativecommons.org/licenses/by/4.0), which permits unrestricted use, distribution, and reproduction in any medium, provided the original work is properly credited. The Creative Commons Public Domain Dedication waiver (http://creativecommons.org/publicdomain/zero/1.0/) applies to the data made available in this article, unless otherwise stated.

prevent further tissue hypoperfusion and organ dysfunction [4-6]. In this regard, fluid administration is still considered the first-choice therapy to restore arterial pressure in most hemodynamic resuscitation protocols [4-6]. However, because arterial pressure results from the interaction between the arterial system and the blood ejected by the heart [7], the response of blood pressure to fluids continues to be a challenge [8-12]. Therefore, even if a patient is able to increase cardiac output $(\mathrm{CO})$ with fluids, the arterial pressure response cannot easily be predicted [13]. So, in order to determine whether fluid administration will improve arterial pressure, it is necessary to evaluate not 
only patients' preload dependency but also their arterial load [14] - that is, the net force imposed on left ventricular ejection that defines, along with left ventricular stroke volume (SV), the arterial pressure [15].

In a previous study, we found that dynamic arterial elastance $\left(\mathrm{Ea}_{\mathrm{dyn}}\right)$, defined as the pulse pressure variation (PPV) to stroke volume variation (SVV) ratio, could predict the arterial pressure increase after volume expansion (VE) in hypotensive, preload-dependent patients [13]. However, because both SVV and PPV were obtained from the pulse pressure analysis, mathematical coupling could not be rejected as a reason for the findings; thus, a validation study was necessary before $\mathrm{Ea}_{\mathrm{dyn}}$ could be recommended for clinical decision-making [16].

The aim of this study was to confirm the usefulness of $E a_{\text {dyn }}$ as a predictor of the arterial pressure response to fluid administration by simultaneously measuring SVV and PPV from two independent signals.

\section{Methods}

This observational study was conducted in the Intensive Care Unit of the Hospital SAS de Jerez during a 1-year period (from July 2012 to July 2013). Approval from our Institutional Research Ethics Committee (Cómite de Ética de la Investigación de Jerez-Sierra-Costa Noroeste, Acta 3, April 2012) was obtained. Informed consent was deemed unnecessary because the study protocol and the monitoring procedures were considered to be part of routine clinical care.

\section{Patients}

We prospectively included all patients equipped with an indwelling arterial catheter and evaluated by esophageal Doppler monitoring who were receiving a fluid challenge for the presence of clinical signs of acute circulatory failure, including hypotension (defined as a MAP $\leq 65 \mathrm{mmHg}$ or a systolic arterial pressure (SAP) $\leq 90 \mathrm{mmHg}$ ); requirement for vasopressor drugs, presence of lactic acidosis, urine output $\leq 0.5 \mathrm{ml} \cdot \mathrm{kg}^{-1} \cdot \mathrm{hr}^{-1}$ during at least 2 hours, heart rate $>100$ beats/min and/or the presence of skin mottling. Preload dependency was assessed according to our institutional protocol for hemodynamic resuscitation and defined as a CO increase $\geq 10 \%$ after a 2 -minute legraising maneuver [17]. In all cases, the final decision to start or continue fluid administration was made by the treating physician.

Patients were under controlled mechanical ventilation with no spontaneous respiratory efforts, as assessed by visual inspection of the airway pressure curve. Patients with unstable cardiac rhythm were excluded, although this condition did not affect the decision to administer fluids.

\section{Hemodynamic monitoring}

Patients were monitored with an esophageal Doppler monitoring system (CardioQ-Combi ${ }^{\text {Tw }}$; Deltex Medical, Chichester, UK). This system combines a standard Doppler monitor with arterial pressure analysis capability. The probe was inserted into the esophagus, preferably using the nasal route, and advanced until the maximal peak velocity of the aortic blood flow was reached. The gain setting was adjusted to obtain the optimum outline of the Doppler waveform. In order to reduce signal noise from heart valves and wall thump artifact, a built-in filter function was activated in some patients and kept unchanged throughout the study.

An arterial pressure transducer (TruWave; Edwards Lifesciences, Irvine, CA, USA) was zeroed to atmospheric pressure, and optimal damping of the arterial waveform was carefully checked by fast-flushing the line. The arterial pressure signal was transferred from the patient's bedside monitor to the Doppler system using a serial cable and automatically synchronized with the aortic blood flow waveform for analysis (Additional file 1: Figure S1).

\section{Arterial load assessment}

Our arterial load assessment was grounded on a basic physiological framework based on a two-element Windkessel model of arterial circulation with static and dynamic components. The static component represents a unique pressure-volume $(\mathrm{P}-\mathrm{V})$ relationship and can be described by a resistive element or the systemic vascular resistance (SVR $=\mathrm{MAP} / \mathrm{CO} * 80)$ and a pulsatile element or the net arterial compliance $(\mathrm{C}=\mathrm{SV} /$ arterial pulse pressure) [18]. This distinction is a product of the oscillatory nature of the arterial flow and the mechanical properties of the arterial system [7]. The effective arterial elastance $\left(\mathrm{Ea}=0.9^{*} \mathrm{SAP} / \mathrm{SV}\right)$ is considered an integrative variable of arterial load that incorporates both steady and pulsatile elements $[15,19,20]$. Dynamic assessment of arterial load was performed by calculating $\mathrm{Ea}_{\mathrm{dyn}}$, which we defined as the ratio between PPV and SVV during a respiratory cycle. Rather than being a steady-state variable, $\mathrm{Ea}_{\mathrm{dyn}}$ depicts the slope of the $\mathrm{P}-\mathrm{V}$ relationship and provides a functional assessment of arterial load [21]. PPV obtained from the arterial line and SVV from the aortic blood flow were simultaneously calculated by using the Doppler monitor software with the standard formulae [22] and averaged over three respiratory cycles (Figure 1). In order to do so, respiratory rate was manually introduced on the Doppler monitor.

\section{Study protocol}

All hemodynamic variables were measured prior to and just after VE, consisting of $500 \mathrm{ml}$ of normal saline given within 30 minutes. No changes in ventilatory settings or vasoactive drugs were made during volume 


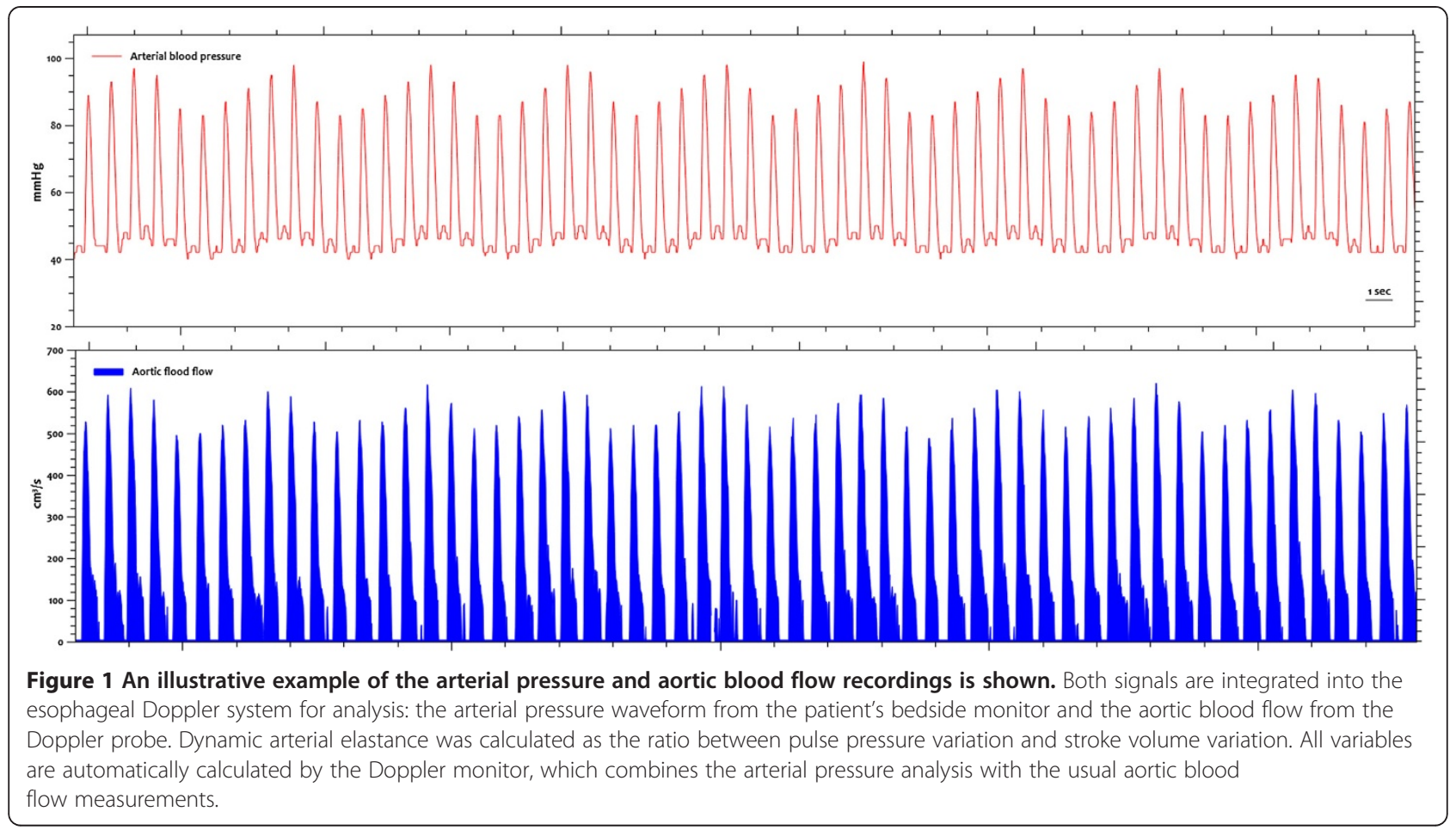

administration. No paralyzing agents were used for the study. All hemodynamic variables were automatically recorded every 10 seconds and averaged over 1 minute for statistical purposes.

\section{Statistical analysis}

The normality of the data distribution was tested using the Kolmogorov-Smirnov test. The results are expressed as mean \pm standard deviation or as median (25th to 75 th interquartile range), as appropriate. Patients were classified as hypotensive if they had a MAP $\leq 65 \mathrm{mmHg}$ and/ or SAP $<90 \mathrm{mmHg}$. Sepsis was defined according to standard criteria [5]. As we selected an increase in CO $\geq 10 \%$ for defining fluid responsiveness, we chose a similar cutoff for MAP changes for defining a positive pressure response. This threshold was selected assuming a matched ventriculoarterial coupling and optimal hydraulic efficiency (maximal stroke work) [23]. The relationships between variables were analyzed using a linear regression analysis. Because changes in arterial pressure depend not only on $\mathrm{Ea}_{\mathrm{dyn}}$ but also on the magnitude of $\mathrm{CO}$ changes, we also calculated the weighted least-squares regression, taking into consideration the contribution of $\mathrm{CO}$ changes in the relationship between arterial pressure increase and preinfusion $\mathrm{Ea}_{\mathrm{dyn}}$. Differences at baseline between pressure responders and non-responders were compared by means of an independent sample $t$-test, and their evolution over time was assessed by one-way analysis of variance with repeated measurements, using group (pressure responders vs. non-responders) as the between- subjects factor and time (preinfusion vs. postinfusion) as the within-subjects factor. Differences between groups were compared using an independent samples $t$-test. Comparison between preinfusion and postinfusion periods was tested using a $t$-test for repeated measurements. Categorical variables were compared using the $x^{2}$ test. For each arterial load variable, a receiver operating characteristic (ROC) curve was created to test the ability of predicting a positive MAP response after VE. Areas under the ROC curve (AUC) with 95\% confidence intervals (95\% CIs) were compared by using the method described by DeLong et al. [24]. Optimal cutoff values were calculated by maximizing the Youden index $(J=$ sensitivity + specificity -1$)$. The diagnostic performance of $\mathrm{Ea}_{\mathrm{dyn}}$ was also assessed on the basis of its positive and negative likelihood ratios (LHRs). A diagnostic variable with potential to influence clinical decisions is usually considered when its positive LHR is $>10$, its negative LHR is $<0.1$ and the AUC is $>0.9$ [25]. A gray zone for $\mathrm{Ea}_{\mathrm{dyn}}$ cutoff was created using a resampling method [26]. In summary, the Youden index for each bootstrapped sample from 1,000 replications of the original study population was calculated, then the median value and the $95 \% \mathrm{CI}$ of these 1,000 optimal cut-offs were obtained. This bootstrapped $95 \%$ CI defines a gray zone around the optimum criterion in which formal conclusions about prediction of MAP response cannot be obtained $[25,26]$.

A preliminary power analysis determined that a sample size of 48 patients was required for detecting an AUC difference of $0.1(\alpha=0.05 ; \beta=0.20$; allocation ratio $=1: 1)$. 
A $P$-value $<0.05$ was considered significant. All statistical analyses were two-tailed and performed using MedCalc statistical software version 14.8.0 [27].

\section{Results}

The patients' characteristics are summarized in Table 1. A total of 80 VEs performed in 53 patients were studied (median, 1 ; interquartile range (IQR): 1 to 2 ; maximum: 3 per patient). Eight VEs were excluded from the analysis because CO did not increase by $\geq 10 \%$, and one was excluded because of the presence of cardiac arrhythmia during recoding. The hemodynamic profiles of these eight non-preload

Table 1 Characteristics and demographic data ${ }^{a}$

\begin{tabular}{|c|c|}
\hline Demographics & Data \\
\hline Age (yr) & $62.7 \pm 14.4$ \\
\hline Sex (men/women) & $31 / 22$ \\
\hline Weight (kg) & $81 \pm 23$ \\
\hline Height (cm) & $167 \pm 8$ \\
\hline APACHE II score at admission & $21 \pm 5$ \\
\hline Plasma lactate level at admission (mmol/L) & $1.9(1.21$ to 3.12$)$ \\
\hline ICU mortality rate, $n(\%)$ & $16(30 \%)$ \\
\hline \multicolumn{2}{|l|}{ Vasoactive drugs at time of inclusion } \\
\hline Norepinephrine, $n$; dose $\left(\mu \mathrm{g} \mathrm{kg}{ }^{-1} \min ^{-1}\right)$ & $30 ; 0.19 \pm 0.14$ \\
\hline Dobutamine, $n$; dose $\left(\mu \mathrm{g} \mathrm{kg}{ }^{-1} \min ^{-1}\right)$ & $13 ; 5 \pm 2$ \\
\hline \multicolumn{2}{|l|}{ Analgesia and sedative drugs } \\
\hline Fentanyl, $n$; dose $\left(\mu \mathrm{g} \mathrm{kg}^{-1} \mathrm{hr}^{-1}\right)$ & $28 ; 1.55 \pm 0.57$ \\
\hline Remifentanil, $n$; dose $\left(\mu \mathrm{g} \mathrm{kg}{ }^{-1} \min ^{-1}\right)$ & $20 ; 0.14 \pm 0.06$ \\
\hline Midazolam, $n$; dose $\left(\mathrm{mg} \mathrm{kg}^{-1} \mathrm{hr}^{-1}\right)$ & $32 ; 0.10 \pm 0.04$ \\
\hline Propofol, $n$; dose $\left(\mathrm{mg} \mathrm{kg}^{-1} \mathrm{hr}^{-1}\right)$ & $3 ; 1.25$ (1 to 2$)$ \\
\hline Morphine, $n$; dose $\left(\mathrm{mg} \mathrm{kg}^{-1} \mathrm{hr}^{-1}\right)$ & $1 ; 1.8$ \\
\hline \multicolumn{2}{|l|}{ Ventilator settings } \\
\hline Tidal volume (ml/kg predicted body weight) & $8(6$ to 10$)$ \\
\hline Respiratory rate (breaths/min) & 19 (18 to 20$)$ \\
\hline Total PEEP $\left(\mathrm{cmH}_{2} \mathrm{O}\right)$ & 8 (6 to 10$)$ \\
\hline \multicolumn{2}{|l|}{ Acute circulatory failure origin, $n(\%)$} \\
\hline Postoperative hypovolemia & $7(13 \%)$ \\
\hline Hemorrhagic shock & $4(8 \%)$ \\
\hline Anoxic encephalopathy & $2(4 \%)$ \\
\hline Toxic poisoning & $2(4 \%)$ \\
\hline Sepsis/septic shock & $32(60 \%)$ \\
\hline Abdominal & 18 \\
\hline Pulmonary & 8 \\
\hline Urological & 2 \\
\hline Neurological & 3 \\
\hline Other & 1 \\
\hline
\end{tabular}

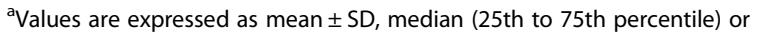
absolute numbers, as appropriate. APACHE II, Acute Physiology and Chronic Health Evaluation II; ICU: intensive care unit; PEEP: positive end-expiratory pressure. responder patients are shown in Additional file 1: Table S1. In seven patients (13\%), the arterial blood pressure was monitored from a femoral arterial catheter. Thirty-two patients $(60 \%)$ had sepsis, mainly from an abdominal source. The patients were studied mostly during the first 24 hours of ICU admission. The heart rate/respiratory rate ratio was $4.9 \pm 0.9$ at preinfusion and $4.7 \pm 0.9$ after VE.

\section{Hemodynamic response to volume expansion}

Hemodynamic changes after VE are shown in Table 2. Overall, VE increased CO by $14.7 \%$ (13.2\% to $19.1 \%)$, SV by $20.1 \%$ (17.1\% to $21.9 \%$ ) and MAP by $9.8 \%$ (4.9 to $10.3 \%$ ). Thirty-three patients (41\%) were classified as pressure responders. Of 32 fluid challenges performed in the 22 hypotensive patients, only 17 showed a MAP increase by $\geq 10 \%$ (53\%). The rate of pressure responders was similar between patients with and without sepsis (34\% vs. 51\%; $P=0.18$ ), or between hypotensive and non-hypotensive patients (53\% vs. $33 \%$; $P=0.13)$. There was a weak relationship between VE-induced changes in MAP and CO $\left(R^{2}=0.05\right.$; $P=0.04$ ) (Figure 2) and between VE-induced changes in arterial pulse pressure and SV $\left(R^{2}=0.13 ; P<0.001\right)$.

\section{Effects of volume expansion on arterial load}

Fluid administration decreased Ea from 1.75 (1.54 to $1.91) \mathrm{mmHg} / \mathrm{ml}$ to 1.59 (1.45 to 1.81$) \mathrm{mmHg} / \mathrm{ml}(P$ $<0.0001)$ and SVR from $1,229 \pm 554 \mathrm{dyn} \cdot \mathrm{s} \cdot \mathrm{cm}^{-5}$ to 1,150 $\pm 514 \mathrm{dyn} \cdot \mathrm{s} \cdot \mathrm{cm}^{-5}(P<0.0001)$. Net arterial compliance did not change. In non-responder patients, VE reduced the static component of arterial load but did not affect $\mathrm{Ea}_{\text {dyn }}$ (Table 3).

At baseline, $\mathrm{Ea}_{\mathrm{dyn}}$ was higher in pressure responder patients $(1.04 \pm 0.28$ vs. $0.60+0.14 ; P<0.0001)$ (Figure 3). Pressure responders were also more hypotensive (Table 2 ). Furthermore, preinfusion $\mathrm{Ea}_{\text {dyn }}$ and SVR were higher in hypotensive patients $\left(\mathrm{Ea}_{\text {dyn }}: 0.90 \pm 0.35\right.$ vs. $0.70 \pm 0.23$, $P<0.01 ; \quad$ SVR: $1,036 \pm 605$ dyn.s.cm ${ }^{-5}$ vs. $1,359 \pm$ 486 dyn.s. $\mathrm{cm}^{-5}, P<0.05$ ) (Additional file 1: Table S2). No differences were observed in preinfusion arterial load variables between septic and non-septic patients (Additional file 1: Table S3).

Preinfusion $\mathrm{Ea}_{\text {dyn }}$ was correlated with VE-induced changes in SAP $\left(R^{2}=0.56 ; P<0.0001\right)$, diastolic arterial pressure (DAP; $\left.R^{2}=0.61 ; P<0.0001\right)$, MAP $\left(R^{2}=0.60\right.$; $P<0.0001)$ and arterial pulse pressure $\left(R^{2}=0.42 ; P<0.0001\right)$ (Figure 4). When adjusted for CO changes, this relationship was higher (SAP: $R^{2}=0.62$; DAP: $R^{2}=0.70$; MAP: $R^{2}=$ 0.69 ; pulse pressure: $R^{2}=0.44 ; P<0.0001$, respectively; Additional file 1: Figures S2 and S3). None of the static components of arterial load were associated with changes in arterial pressure produced by VE. No relationship was observed between $\mathrm{Ea}_{\mathrm{dyn}}$ and other variables of arterial load at baseline or after VE. 
Table 2 Effects of volume expansion in hemodynamic variables according to mean arterial pressure increase ${ }^{a}$

\begin{tabular}{|c|c|c|c|}
\hline & Before volume expansion & After volume expansion & $P$-value ${ }^{b}$ \\
\hline \multicolumn{4}{|l|}{$\mathrm{CO}, \mathrm{L} / \mathrm{min}$} \\
\hline Responders & $4.9 \pm 2.2$ & $5.8 \pm 2.5^{c}$ & \multirow[t]{2}{*}{0.581} \\
\hline Non-responders & $5.9 \pm 2.3$ & $6.8 \pm 2.6^{c}$ & \\
\hline \multicolumn{4}{|l|}{ Heart rate, beats/min } \\
\hline Responders & $91 \pm 21$ & $86 \pm 19^{c}$ & \multirow[t]{2}{*}{0.036} \\
\hline Non-responders & $92 \pm 17$ & $90 \pm 17^{c}$ & \\
\hline \multicolumn{4}{|l|}{$\mathrm{SV}, \mathrm{ml}$} \\
\hline Responders & $56 \pm 24$ & $69 \pm 26^{c}$ & \multirow[t]{2}{*}{0.971} \\
\hline Non-responders & $65 \pm 27$ & $77 \pm 33^{c}$ & \\
\hline \multicolumn{4}{|l|}{$\mathrm{CPO}, \mathrm{W}$} \\
\hline Responders & $0.7 \pm 0.3^{d}$ & $1.0 \pm 0.4^{c}$ & \multirow[t]{2}{*}{$<0.001$} \\
\hline Non-responders & $0.9 \pm 0.3$ & $1.1 \pm 0.4^{c}$ & \\
\hline \multicolumn{4}{|l|}{ MAP, mmHg } \\
\hline Responders & $67 \pm 15^{d}$ & $80 \pm 18^{c}$ & \multirow[t]{2}{*}{$<0.001$} \\
\hline Non-responders & $74 \pm 12$ & $76 \pm 12^{c}$ & \\
\hline \multicolumn{4}{|l|}{ SAP, mmHg } \\
\hline Responders & $102 \pm 18^{d}$ & $128 \pm 22^{c}$ & \multirow[t]{2}{*}{$<0.001$} \\
\hline Non-responders & $113 \pm 18$ & $118 \pm 20^{*}$ & \\
\hline \multicolumn{4}{|l|}{$\mathrm{DAP}, \mathrm{mmHg}$} \\
\hline Responders & $51 \pm 13$ & $57 \pm 14^{c}$ & \multirow[t]{2}{*}{$<0.001$} \\
\hline Non-responders & $55 \pm 11$ & $55 \pm 11$ & \\
\hline \multicolumn{4}{|l|}{$\mathrm{PP}, \mathrm{mmHg}$} \\
\hline Responders & $51 \pm 17$ & $70 \pm 20^{c}$ & \multirow[t]{2}{*}{$<0.001$} \\
\hline Non-responders & $58 \pm 15$ & $64 \pm 17^{c}$ & \\
\hline \multicolumn{4}{|l|}{ PPV, \% } \\
\hline Responders & $18 \pm 7^{d}$ & $9 \pm 5^{c}$ & \multirow[t]{2}{*}{$<0.001$} \\
\hline Non-responders & $11 \pm 5$ & $8 \pm 4^{c}$ & \\
\hline \multicolumn{4}{|l|}{ SW, \% } \\
\hline Responders & $17 \pm 8$ & $15 \pm 7^{c}$ & \multirow[t]{2}{*}{0.135} \\
\hline Non-responders & $18 \pm 7$ & $15 \pm 5^{c}$ & \\
\hline
\end{tabular}

${ }^{\mathrm{a}}$ Responders are defined by a mean arterial pressure (MAP) increase $\geq 10 \%$ ). Data are expressed as mean \pm SD. ${ }^{\mathrm{b}} P$-values refer to group (responder vs. non-responder) and time (preinfusion vs. postinfusion) interaction using analysis of variance for repeated measurements. ${ }^{C} P<0.05$ vs. before volume expansion. ${ }^{\dagger} P<0.05$ vs. non-responders. CO, Cardiac output; CPO, Cardiac power output (mean arterial pressure $\times$ cardiac output/451); DAP, Diastolic arterial pressure; MAP, Mean arterial pressure; PP, Pulse pressure (systolic pressure minus diastolic pressure); PPV, Arterial pulse pressure variation; SAP, Systolic arterial pressure; SV, Stroke volume; SV, Stroke volume variation.

\section{Prediction of arterial pressure increase after volume expansion}

The AUC for preinfusion $\mathrm{Ea}_{\text {dyn }}(0.94 \pm 0.03 ; 95 \% \mathrm{CI}: 0.86$ to 0.98$)$ was higher than for any other variable of arterial load: Ea (0.53 $\pm 0.07 ; 95 \% \mathrm{CI}: 0.42$ to $0.65 ; P<0.0001), \mathrm{C}$ $(0.51 \pm 0.07 ; 95 \% \mathrm{CI}: 0.39$ to $0.62 ; P<0.0001)$; SVR $(0.55$ \pm 0.07 ; $95 \% \mathrm{CI}: 0.44$ to $0.66 ; P<0.0001)$ and preinfusion MAP $(0.62 \pm 0.07 ; 95 \%$ CI: 0.50 to $0.72 ; P<0.0001)$ (Figure 5).

At baseline, an $\mathrm{Ea}_{\text {dyn }}$ value $\geq 0.73$ predicted an increase $\geq 10 \%$ in MAP after VE with a sensitivity of $90.9 \%(95 \%$ CI: $75.7 \%$ to $98.1 \%$ ) and a specificity of $91.5 \%$ (95\% CI:
$79.6 \%$ to $97.6 \%$ ), with a positive predictive value of 88.2 (95\% CI: $72.5 \%$ to $96.7 \%$ ) and a negative predictive value of 93.5 (95\% CI: $82.1 \%$ to $98.6 \%$ ). The positive and negative LHRs for $\mathrm{Ea}_{\mathrm{dyn}}$ were 10.68 (95\% CI: 4.2 to 27.4) and 0.1 (95\% CI: 0.03 to 0.3 ), respectively. The bootstrapped 95\% CI defined a gray zone for $\mathrm{Ea}_{\text {dyn }}$ ranging between 0.72 and 0.88 . Only ten fluid challenges $(12.5 \%)$ were situated in the inconclusive zone.

When only the first VE per patient was included in the analysis, the predictive performance of $\mathrm{Ea}_{\text {dyn }}$ was similar (AUC: $0.92 \pm 0.04 ; 95 \% \mathrm{CI}: 0.81$ to 0.98 ; $P=0.64$ vs. including all fluid challenges) (Additional file 1: Figure S4). 


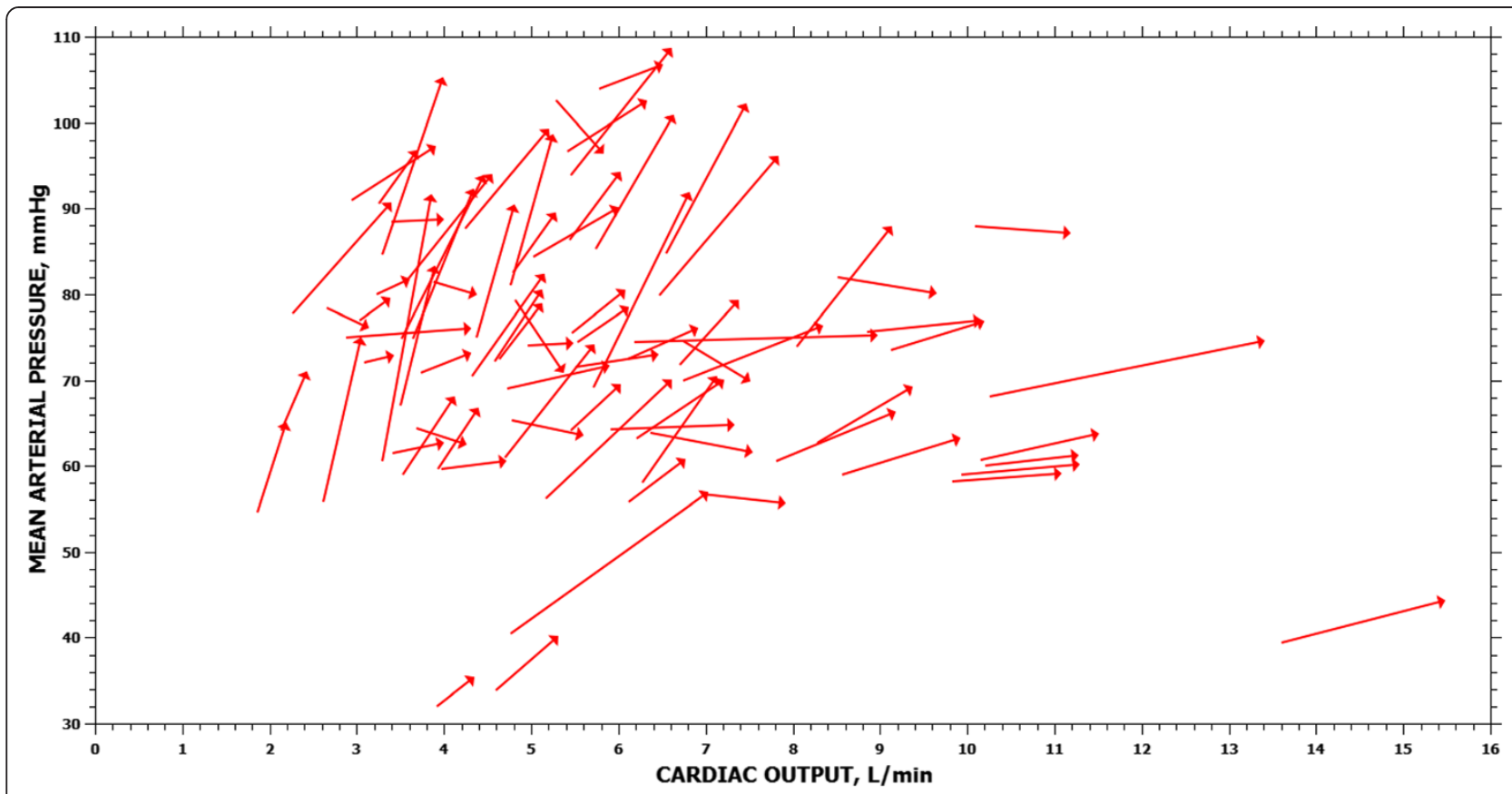

Figure 2 Individual changes in cardiac output and mean arterial pressure after fluid administration.

When we considered an increase of CO and MAP $\geq 15 \%$ for defining a positive preload and pressure response, the AUC of $\mathrm{Ea}_{\text {dyn }}$ was also excellent: $0.97 \pm 0.03$ (95\% CI: 0.86 to $0.99 ; P=0.37$ vs. definition of $\geq 10 \%$ for $\mathrm{CO}$ and MAP increases) (Additional file 1: Figure S5). Because the impact of PPV seems to be predominant on the $\mathrm{Ea}_{\text {dyn }}$ ratio, we also compared the performance of PPV alone against $\mathrm{Ea}_{\mathrm{dyn}}$ (AUC for PPV: 0.76; 95\% CI: 0.65 to $0.85 ; P<0.001$ vs. AUC for $\mathrm{Ea}_{\mathrm{dyn}}$ ) (Additional file 1:
Figure S6). The ability of Ea $\mathrm{a}_{\mathrm{dyn}}$ for predicting pressure responsiveness was similar between hypotensive and non-hypotensive patients, as well as between septic and non-septic patients (Additional file 1: Tables S4 and S5).

\section{Discussion}

In this study, we confirmed the ability of $\mathrm{Ea}_{\mathrm{dyn}}$ for predicting arterial pressure response to VE in preload-dependent patients with acute circulatory failure. The greatest strength of

Table 3 Effects of fluid administration on static and dynamic arterial load variables according to mean arterial pressure increase $^{\mathrm{a}}$

\begin{tabular}{|c|c|c|c|}
\hline & Before volume expansion & After volume expansion & $P$-value \\
\hline \multicolumn{4}{|l|}{$E a_{d y n}$} \\
\hline Responders & $1.04 \pm 0.28^{c}$ & $0.62 \pm 0.27^{d}$ & \multirow[t]{2}{*}{$<0.001$} \\
\hline Non-responders & $0.60 \pm 0.14$ & $0.59 \pm 0.23$ & \\
\hline \multicolumn{4}{|l|}{$\mathrm{Ea}, \mathrm{mmHg} / \mathrm{ml}$} \\
\hline Responders & $1.89 \pm 0.77$ & $1.89 \pm 0.68$ & \multirow[t]{2}{*}{$<0.001$} \\
\hline Non-responders & $1.82 \pm 0.76$ & $1.58 \pm 0.62^{d}$ & \\
\hline \multicolumn{4}{|l|}{ C, $\mathrm{ml} / \mathrm{mmHg}$} \\
\hline Responders & $1.11 \pm 0.36$ & $0.99 \pm 0.34^{d}$ & \multirow[t]{2}{*}{$<0.001$} \\
\hline Non-responders & $1.17 \pm 0.57$ & $1.27 \pm 0.60^{d}$ & \\
\hline \multicolumn{4}{|l|}{$S V R$, dyn $\cdot s \cdot \mathrm{cm}^{-5}$} \\
\hline Responders & $1282 \pm 572$ & $1293 \pm 548$ & \multirow[t]{2}{*}{$<0.001$} \\
\hline Non-responders & $1192 \pm 545$ & $1050 \pm 469^{d}$ & \\
\hline
\end{tabular}

${ }^{a}$ Responders were defined as mean arterial pressure increase $\geq 10 \%$ after fluid administration. Data are expressed as mean \pm SD. ${ }^{b} P$-values refer to group (responders vs. non-responders) and time (preinfusion vs. postinfusion) interaction using analysis of variance for repeated measurements. ${ }^{c} P<0.0001$ vs. non-responders. ${ }^{\mathrm{d}} P<0.0001$ vs. before volume expansion. $C$, Net arterial compliance; Ea, Effective arterial elastance; Ea $\mathrm{dyn}$ Dynamic arterial elastance; SVR, Systemic vascular resistance. 
our findings is that both SVV and PPV were simultaneously obtained from two independent signals: esophageal Doppler monitor-derived aortic blood flow and the arterial waveform from a routine arterial line. So, mathematical coupling can be excluded. Moreover, the predictive performance of $\mathrm{Ea}_{\mathrm{dyn}}$ was similar between septic and non-septic patients and regardless of the presence of systemic hypotension.

Maintaining a constant perfusion pressure against a variable $\mathrm{CO}$ is a hallmark function of an efficient cardiovascular system $[23,28]$. Arterial pressure can be considered as a complex interface between the blood ejected by the heart, which is modulated to meet the metabolic demands of the organism, and the arterial vascular tree, an adaptive system influenced by its physical proprieties, neurohormonal factors and baroreflex function [29]. Arterial hypotension, therefore, is the pathological consequence of loss of balance between these determinants and often represents the first sign of an acute decompensated cardiovascular system $[23,28]$.

When hypotension occurs, fluid administration remains as the first recommended therapy for restoring arterial pressure in current hemodynamic resuscitation protocols [4-6]. However, the assumption that increasing $\mathrm{CO}$ will be followed by an increase to the same extent in blood pressure is not often true [8-12], and vasopressors are frequently introduced when an arbitrary amount of fluids has been administered [4,5]. So, as long as no physiological trigger for the timing of vasopressor support is established, aggressive volume resuscitation, if aimed to a pressure target, could lead to fluid overload, delayed vasoactive therapy or even increased mortality risk [30].

On the basis of the functional hemodynamic concept [31], $\mathrm{Ea}_{\text {dyn }}$ was originally conceived to answer an eminently clinical question: If a patient is fluid-responsive, will arterial pressure improve with volume administration [14]? Taking advantage of well-known hemodynamic effects of intermittent positive pressure ventilation on left ventricular SV and arterial pressure [32], $\mathrm{Ea}_{\text {dyn }}$ depicts the slope of the $\mathrm{P}-\mathrm{V}$ curve during a respiratory cycle, allowing the assessment of pressure responsiveness or, put another way, defining the flow dependency of arterial pressure. Consequently, if $\mathrm{Ea}_{\text {dyn }}$ is high and the patient is preloaddependent, arterial pressure will improve along with $\mathrm{CO}$ after VE. On the contrary, if $\mathrm{Ea}_{\mathrm{dyn}}$ is low, even if the patient is fluid-responsive, VE will not increase blood pressure and vasopressors should be considered in order to correct hypotension. Moreover, for the same increase in $\mathrm{CO}$, the greater the preinfusion $\mathrm{Ea}_{\mathrm{dyn}}$, the greater the improvement in arterial pressure after VE. In our study, an $\mathrm{Ea}_{\mathrm{dyn}}$ value of 0.73 predicted pressure responsiveness with a high sensitivity and specificity and a narrow gray zone of uncertainty. Interestingly, this threshold is close to the value found in our previous study [13] and similar to that suggested in the original publication [14].

It is noteworthy that $\mathrm{Ea}_{\text {dyn }}$ should not be interpreted as an actual variable of arterial load or arterial tone, but as a functional measure of arterial load. Therefore, in the same way that neither PPV nor SVV is an index of cardiac preload, $\mathrm{Ea}_{\mathrm{dyn}}$ should not be considered a direct 


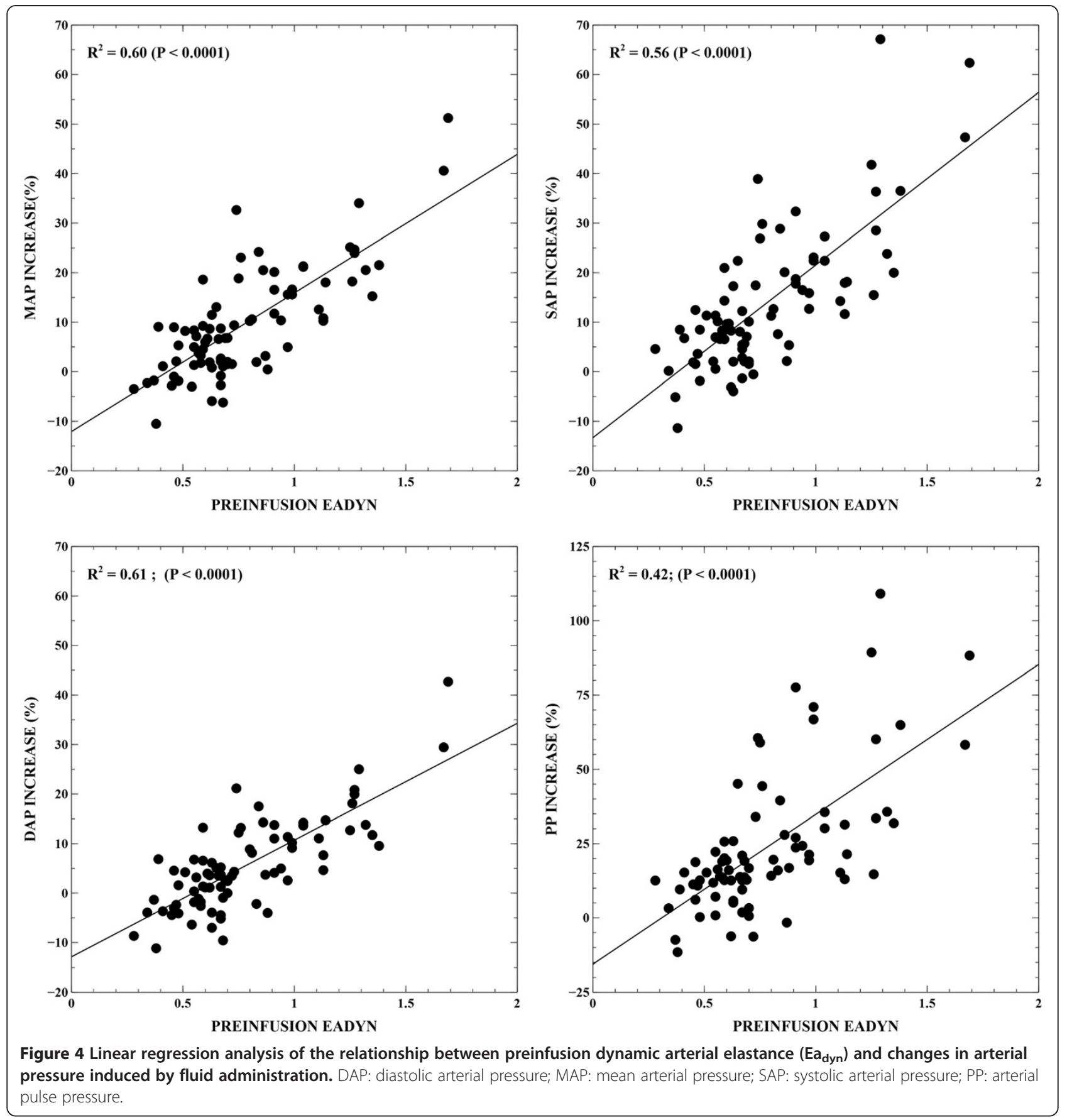

measure of arterial load. The lack of relationship observed in this study between static variables and $\mathrm{Ea}_{\mathrm{dyn}}$ supports this hypothesis.

In our previous study, we observed that none of the static arterial load variables predicted the subsequent arterial pressure response to VE [13]. Our presently reported results confirm this observation in a larger group of patients with a different methodology. Although the lack of prediction of static variables of arterial load could be explained by several hypotheses, one reason that might be argued is that our arterial load framework, although physiologically reasonable, provides only a gross oversimplification of the actual nature of arterial system that ignores, for example, the phenomenon of pressure wave reflection [29]. A fuller characterization of arterial load requires a frequency domain assessment using technology outside the scope of routine hemodynamic monitoring $[15,19]$. However, we think that another explanation could be that the $\mathrm{P}-\mathrm{V}$ relationship is not constant, because it can be also affected by age, sex or pathological conditions, 


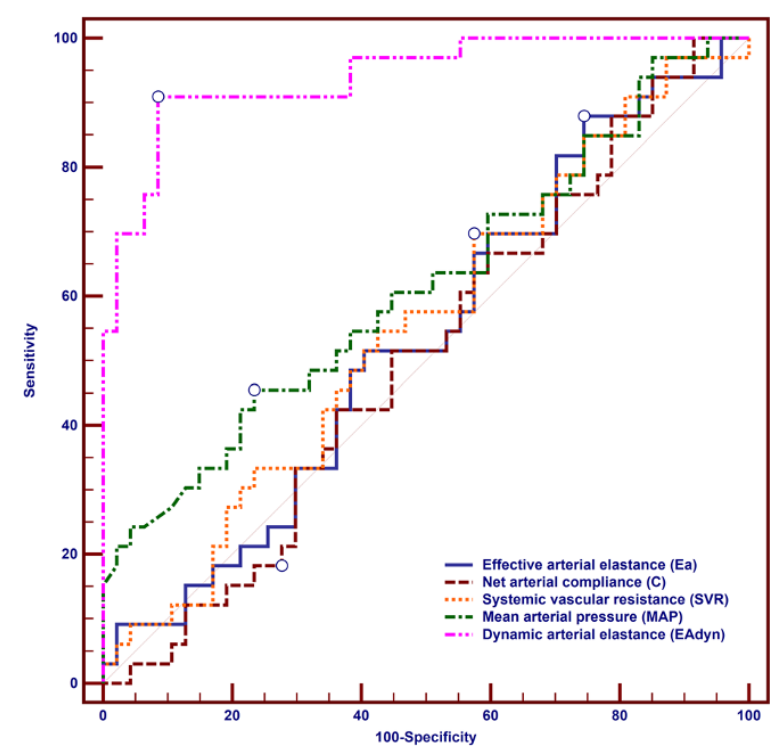

Figure 5 Comparison of receiver operating characteristic curves for testing the ability of static and dynamic arterial load variables to detect a mean arterial pressure increase $\geq 10 \%$ after volume administration. Dynamic arterial elastance $\left(E_{\mathrm{d}} \mathrm{dyn}\right)=$ area under the receiver operating characteristic curve (AUC): 0.94 (95\% Cl: 0.86 to 0.98); effective arterial elastance (Ea) = AUC: 0.53 ( $95 \%$ Cl: 0.42 to 0.65$)$; systemic vascular resistance (SVR) = AUC: 0.55 ( $95 \%$ Cl: 0.44 to 0.66); net arterial compliance (C) = AUC: 0.51 (95\% Cl: 0.39 to 0.62$)$; preinfusion MAP = AUC: 0.62 (95\% Cl: 0.50 to 0.72 ).

such us septic shock or arterial hypertension [33]. So, even in the same patient, a single steady-state $\mathrm{P}-\mathrm{V}$ relationship could be associated to different slopes and hence different $\mathrm{Ea}_{\text {dyn }}$ values.

Our study has some limitations that need to be mentioned. First, we decided to use the esophageal Doppler monitor for estimating CO and SVV. This is a wellvalidated method with proved benefits for guiding fluid therapy during the perioperative period [34]. However, because this technique assumes a constant proportion of $\mathrm{CO}$ through the descending aorta and a fixed aortic diameter, changes in flow distribution to the upper part of the body or variations in aortic diameter induced by arterial pressure changes could potentially affect its capability to detect $\mathrm{CO}$ changes [35]. Moreover, the ability of esophageal Doppler monitoring for tracking beat-to-beat changes in SV, as may occur during an inferior vena cava occlusion, has raised some concerns about the accuracy of this method for calculating SVV [36,37]. More recently, two clinical studies have demonstrated the usefulness of SVV measured by esophageal Doppler monitoring for predicting fluid responsiveness in surgical patients $[38,39]$. Despite these limitations, we chose esophageal Doppler monitoring because of its ability to detect rapid hemodynamic changes and its low dependency on arterial tone variations, unlike pulse pressure analysis-based systems [40]. Specifically, our monitor combines the standard Doppler method with the arterial pressure analysis, allowing the simultaneous assessment of both flow and pressure, and the automatic calculation of arterial load variables.

A second limitation is that we included preloaddependent patients, regardless of their baseline MAP levels. Obviously, measuring $\mathrm{Ea}_{\mathrm{dyn}}$ should be considered primarily in hypotensive patients. However, we think that knowing whether arterial pressure will improve with fluids could also be of interest for the clinician, because some patients could benefit from fluids administered in order to decrease their vasopressor dosage [41]. Finally, given that a predefined level of MAP does not guarantee an adequate perfusion pressure to all tissues and cannot be generalized to all patients, hemodynamic resuscitation should be targeted not only at restoring perfusion pressure but also at providing a sufficient oxygen delivery to guarantee an adequate cellular metabolism [2]. However, correction of arterial hypotension seems to be a necessary condition for normal cellular function [1].

\section{Conclusions}

$\mathrm{Ea}_{\mathrm{dyn}}$ obtained from two independent signals allowed the prediction of arterial pressure response to fluid administration in mechanically ventilated, preload-dependent patients with acute circulatory failure. The clinical applicability of $\mathrm{Ea}_{\mathrm{dyn}}$ seems now purely limited by technological boundaries. Only its implementation in future hemodynamic resuscitation protocols will determine the impact of $\mathrm{Ea}_{\mathrm{dyn}}$ in patient outcome.

\section{Key messages}

- Dynamic arterial elastance $\left(\mathrm{Ea}_{\mathrm{dyn}}\right)$, defined as the ratio between pulse pressure variation (PPV) and stroke volume variation (SVV), measured from two independent signals, predicted the arterial pressure response to fluid administration in mechanically ventilated, preload-dependent patients.

- $A n \mathrm{Ea}_{\mathrm{dyn}}$ value $\geq 0.73$ predicted a mean arterial pressure increase $\geq 10 \%$ after volume expansion with $90.9 \%$ sensitivity and $91.5 \%$ specificity, as well as a narrow gray zone ranging between 0.72 and 0.88 . The predictive performance of $\mathrm{Ea}_{\mathrm{dyn}}$ was similar in septic and nonseptic patients and regardless of the presence of systemic hypotension.

- The arterial pressure response to volume administration was not related to static arterial load variables.

- Preload-dependent patients in whom arterial pressure did not increase after volume expansion showed a decrease in the static component of arterial load. 


\section{Additional file}

\section{Additional file 1: Supplementary information and data.}

\section{Abbreviations}

AUC: Area under the receiver operating characteristic curve; C: Net arterial compliance; Cl: Confidence interval; CO: Cardiac output; DAP: Diastolic arterial pressure; Ea: Effective arterial elastance; Ea $a_{\text {dyn: }}$ Dynamic arterial elastance; ICU: Intensive care unit; IQR: Interquartile range; LHR: Likelihood ratio; MAP: Mean arterial pressure; ROC: Receiver operating characteristic; SAP: Systolic arterial pressure; SD: Standard deviation; SV: Stroke volume; SVR: Systemic vascular resistance; VE: Volume expansion.

\section{Competing interests}

MIMG is a consultant for Edwards Lifesciences and has received travel expenses from Deltex. AGC has received honoraria from Edwards Lifesciences. AR has received honoraria from and has served on the advisory board for LiDCO, and he has received honoraria from Covidien, Edwards Lifesciences and Cheetah. MC has received within the past 5 years, honoraria and/or travel expenses from Edwards Lifesciences, LiDCO, Cheetah, Bmeye, Masimo and Deltex. HDA has received travel expenses from LiDCO and research support from Applied Physiology. MGR and RMG declare that they have no competing interests.

\section{Authors' contributions}

MIMG conceived of and designed the study, participated in the recruitment of patients, performed the statistical analysis, interpreted the data and wrote the manuscript. MGR participated in the study design, patient recruitment and data collection, provided technical support and contributed in the critical review of the manuscript. AGC participated in the study conception and design, interpreted data, contributed in the critical review and helped to draft the manuscript. DHA, AR and RMG made substantial contributions to the analysis and interpretation of data, were involved in drafting the manuscript and contributed to the critical review. MC contributed to the conception and design of the study, interpreted data and wrote and reviewed the manuscript. All authors read and approved the final manuscript.

\section{Acknowledgments}

The authors thank the nursing staff at the intensive care unit of the Hospital SAS de Jerez for their assistance with this study. We thank Deltex Medical for providing CardioQ-Combi ${ }^{\mathrm{TM}}$ monitor. Except for the esophageal Doppler monitor, all support was received solely from institutional and/or departmental sources. The results of this study were presented in part in the 26th Annual Congress of the European Society of Intensive Care Medicine (ESICM, October 2013, Paris) and at the X Congreso Panamericano e Ibérico de Medicina Crítica y Terapia Intensiva/XLIX Congreso Nacional de la Sociedad Española de Medicina Intensiva, Crítica y Unidades Coronarias (SEMICYUC, June 2014, Madrid).

Received: 16 August 2014 Accepted: 28 October 2014 Published online: 19 November 2014

\section{References}

1. Vincent JL, De Backer D: Circulatory shock. N Engl J Med 2013, 369:1726-1734.

2. Pinsky MR: Both perfusion pressure and flow are essential for adequate resuscitation. Sepsis 2000, 4:143-146.

3. LeDoux D, Astiz ME, Carpati CM, Rackow EC: Effects of perfusion pressure on tissue perfusion in septic shock. Crit Care Med 2000, 28:2729-2732.

4. Antonelli M, Levy M, Andrews PJ, Chastre J, Hudson LD, Manthous C, Meduri GU, Moreno RP, Putensen C, Stewart T, Torres A: Hemodynamic monitoring in shock and implications for management. International Consensus Conference, Paris, France, 27-28 April 2006. Intensive Care Med 2007, 33:575-590.

5. Dellinger RP, Levy MM, Carlet JM, Bion J, Parker MM, Jaeschke R, Reinhart K, Angus DC, Brun-Buisson C, Beale R, Calandra T, Dhainaut JF, Gerlach H, Harvey M, Marini JJ, Marshall J, Ranieri M, Ramsay G, Sevransky J, Thompson BT, Townsend S, Vender JS, Zimmerman JL, Vincent JL: Surviving Sepsis
Campaign: international guidelines for management of severe sepsis and septic shock: 2008. Intensive Care Med 2008, 34:17-60.

6. Ochagavía A, Baigorri F, Mesquida J, Ayuela JM, Ferrándiz A, García X, Monge MI, Mateu L, Sabatier C, Clau-Terré F, Vicho R, Zapata L, Maynar J, Gil A, Grupo de Trabajo de Cuidados Intensivos Cardiológicos y RCP de la SEMICYUC: [Hemodynamic monitoring in the critically patient: recommendations of the Cardiological Intensive Care and CPR Working Group of the Spanish Society of Intensive Care and Coronary Units] [Article in Spanish]. Med Intensiva 2014, 38:154-169.

7. Nichols WW, O'Rourke M: The nature of flow of a liquid. In McDonald's Blood Flow in Arteries: Theoretical, Experimental and Clinical Principles. 5th edition. Edited by Nichols WW, O'Rourke M. London: Oxford University Press; 2005:11-48.

8. Pierrakos C, Velissaris D, Scolletta S, Heenen S, De Backer D, Vincent JL: Can changes in arterial pressure be used to detect changes in cardiac index during fluid challenge in patients with septic shock? Intensive Care Med 2012, 38:422-428.

9. Dufour N, Chemla D, Teboul JL, Monnet X, Richard C, Osman D: Changes in pulse pressure following fluid loading: a comparison between aortic root (non-invasive tonometry) and femoral artery (invasive recordings). Intensive Care Med 2011, 37:942-949.

10. Lakhal K, Ehrmann S, Perrotin D, Wolff M, Boulain T: Fluid challenge: tracking changes in cardiac output with blood pressure monitoring (invasive or non-invasive). Intensive Care Med 2013, 39:1953-1962.

11. Monnet X, Letierce A, Hamzaoui O, Chemla D, Anguel N, Osman D, Richard C, Teboul $\mathrm{J}$ : Arterial pressure allows monitoring the changes in cardiac output induced by volume expansion but not by norepinephrine. Crit Care Med 2011, 39:1394-1399.

12. Le Manach Y, Hofer CK, Lehot JJ, Vallet B, Goarin JP, Tavernier B, Cannesson $\mathrm{M}$ : Can changes in arterial pressure be used to detect changes in cardiac output during volume expansion in the perioperative period? Anesthesiology 2012, 117:1165-1174

13. Monge García MI, Gil Cano A, Gracia Romero M: Dynamic arterial elastance to predict arterial pressure response to volume loading in preloaddependent patients. Crit Care 2011, 15:R15.

14. Pinsky MR: Protocolized cardiovascular management based on ventricular-arterial coupling. In Functional Hemodynamic Monitoring. Edited by Pinsky MR, Payen D. Berlin: Springer-Verlag; 2006:381-395.

15. Sunagawa K, Maughan WL, Burkhoff D, Sagawa K: Left ventricular interaction with arterial load studied in isolated canine ventricle. Am J Physiol 1983, 245:H773-H780.

16. Pinsky MR: Defining the boundaries of bedside pulse contour analysis: dynamic arterial elastance. Crit Care 2011, 15:120.

17. Monnet $X$, Teboul JL: Assessment of volume responsiveness during mechanical ventilation: recent advances. Crit Care 2013, 17:217.

18. Chemla D, Hébert JL, Coirault C, Zamani K, Suard I, Colin P, Lecarpentier Y: Total arterial compliance estimated by stroke volume-to-aortic pulse pressure ratio in humans. Am J Physiol 1998, 274:H500-H505.

19. Kelly RP, Ting CT, Yang TM, Liu CP, Maughan WL, Chang MS, Kass DA: Effective arterial elastance as index of arterial vascular load in humans. Circulation 1992, 86:513-521.

20. Segers $P$, Stergiopulos N, Westerhof N: Relation of effective arterial elastance to arterial system properties. Am J Physiol Heart Circ Physio 2002, 282:H1041-H1046.

21. Pinsky MR: Functional hemodynamic monitoring: applied physiology at the bedside. In Yearbook of Intensive Care and Emergency Medicine. Edited by Vincent JL. Heidelberg: Springer-Verlag; 2002:534-551.

22. Michard F, Teboul JL: Using heart-lung interactions to assess fluid responsiveness during mechanical ventilation. Crit Care 2000, 4:282-289.

23. Guarracino F, Baldassarri R, Pinsky MR: Ventriculo-arterial decoupling in acutely altered hemodynamic states. Crit Care 2013, 17:213.

24. DeLong ER, DeLong DM, Clarke-Pearson DL: Comparing the areas under two or more correlated receiver operating characteristic curves: a nonparametric approach. Biometrics 1988, 44:837-845.

25. Ray $P$, Le Manach Y, Riou B, Houle TT: Statistical evaluation of a biomarker. Anesthesiology 2010, 112:1023-1040.

26. Cannesson M, Le Manach Y, Hofer CK, Goarin JP, Lehot JJ, Vallet B, Tavernier $B$ : Assessing the diagnostic accuracy of pulse pressure variations for the prediction of fluid responsiveness: a "gray zone" approach. Anesthesiology 2011, 115:231-241.

27. MedCalc Statistical Software, MedCalc Software bvba, Ostend, Belgium; 2014. [http://www.medcalc.org] 
28. Lamia B, Chemla D, Richard C, Teboul JL: Clinical review: interpretation of arterial pressure wave in shock states. Crit Care 2005, 9:601-606.

29. Nichols WW, O'Rourke M: McDonald's Blood Flow in Arteries: Theoretical, Experimental and Clinical principles. 5th edition. London: Oxford University Press; 2005.

30. Beck V, Chateau D, Bryson GL, Pisipati A, Zanotti S, Parrillo JE, Kumar A: Timing of vasopressor initiation and mortality in septic shock: a cohort study. Crit Care 2014, 18:R97.

31. Garcia X, Pinsky MR: Clinical applicability of functional hemodynamic monitoring. Ann Intensive Care 2011, 1:35.

32. Pinsky MR: Heart lung interactions during mechanical ventilation. Curr Opin Crit Care 2012, 18:256-260.

33. Nichols WW. O'Rourke M: Contours of pressure and flow waves in arteries. In McDonald's Blood Flow in Arteries: Theoretical, Experimental and Clinical principles. 5th edition. Edited by Nichols WW, O'Rourke M. London: Oxford University Press; 2005:165-191.

34. Peyton PJ, Chong SW: Minimally invasive measurement of cardiac output during surgery and critical care: a meta-analysis of accuracy and precision. Anesthesiology 2010, 113:1220-1235.

35. Monnet X, Chemla D, Osman D, Anguel N, Richard C, Pinsky MR, Teboul JL: Measuring aortic diameter improves accuracy of esophageal Doppler in assessing fluid responsiveness. Crit Care Med 2007, 35:477-482.

36. Gunn SR, Kim HK, Harrigan PW, Pinsky MR: Ability of pulse contour and esophageal Doppler to estimate rapid changes in stroke volume. Intensive Care Med 2006, 32:1537-1546.

37. Marquez J, McCurry K, Severyn DA, Pinsky MR: Ability of pulse power, esophageal Doppler, and arterial pulse pressure to estimate rapid changes in stroke volume in humans. Crit Care Med 2008, 36:3001-3007.

38. Guinot PG, de Broca B, Abou Arab O, Diouf M, Badoux L, Bernard E, Lorne E, Dupont $\mathrm{H}$ : Ability of stroke volume variation measured by oesophageal Doppler monitoring to predict fluid responsiveness during surgery. $\mathrm{Br}\rfloor$ Anaesth 2013, 110:28-33.

39. Guinot PG, de Broca B, Bernard E, Abou Arab O, Lorne E, Dupont H: Respiratory stroke volume variation assessed by oesophageal Doppler monitoring predicts fluid responsiveness during laparoscopy. $\mathrm{Br} J$ Anaesth 2014, 112:660-664.

40. Monge Garcia MI, Gracia Romero M, Gil Cano A, Rhodes A, Grounds RM, Cecconi M: Impact of arterial load on the agreement between pulse pressure analysis and esophageal Doppler. Crit Care 2013, 17:R113.

41. Vos JJ, Kalmar AF, Struys MM, Wietasch JK, Hendriks HG, Scheeren TW: Comparison of arterial pressure and plethysmographic waveform-based dynamic preload variables in assessing fluid responsiveness and dynamic arterial tone in patients undergoing major hepatic resection. Br J Anaesth 2013, 110:940-946.

doi:10.1186/s13054-014-0626-6

Cite this article as: García et al:: Dynamic arterial elastance as a predictor of arterial pressure response to fluid administration: a validation study. Critical Care 2014 18:626.

\section{Submit your next manuscript to BioMed Central and take full advantage of:}

- Convenient online submission

- Thorough peer review

- No space constraints or color figure charges

- Immediate publication on acceptance

- Inclusion in PubMed, CAS, Scopus and Google Scholar

- Research which is freely available for redistribution
C Biomed Central 